\title{
Assessment and Funding
}

It is the quality that validates any assessment of merit. In Brazil, the continuing improvement and assessment of the graduate programs has been assured by CAPES (Coordination of Improvement of the Personnel of Higher Education) in the evaluation of graduate programs, and by $C N P q$, (National Council for Scientific and Technological Development) in evaluating individual researchers. This continued assessment has gradually consolidated a virtuous relationship with the research funding organizations. Thus, assessment is not a mere academic exercise: it provides subsidies for the decision makers all down the line, starting with the student who may opt for supervision by competent professors, both scientifically productive and recognized by their peers, and up to both private and public entities, to select which groups and projects are worthy of funding.

CAPES just finished the 2007 Triennial Assessment of the Graduate programs, which includes analysis of the performance of all Brazilian Master's and $\mathrm{PhD}$ programs in the 2004-2006 period. In the evaluation, the level of requirements raised, synchronic with the enhancement of the Brazilian scientific production, which in 20 years was increased 9 times (while the world as a whole just doubled). In 1984, Brazilian chemistry produced only 0.25 international articles per faculty member, and this productivity index raised to 2.3 articles per faculty member in 2006. The constant increase in the parameters used for evaluation of quality, together with the growing use of informatics, statistics and transparency are the basic characteristics for the assessment process used by CAPES.

It is this constant increase in quality requirements that promoted Brazil ascend in chemistry and in the formation of $\mathrm{PhDs}$ which, in 20 years, have increased by tenfold (from less than $40 \mathrm{PhDs}$ in Chemistry in 1984, to approximately 400 in 2006). The main product of a graduate program is neither articles and books, nor theses and dissertations, but those students graduating with Master's and $\mathrm{PhD}$ degrees, who will apply the knowledge and experience gained in the graduate training and, in the case of Chemistry, more and more in non academic institutions, in close collaboration with them.

The high quality of the theses and dissertations have been demonstrated through international publications and/or patents $(63 \%$ of over 8100 articles published in Chemistry in the 2004-2006 period included students as co-authors). Currently, Chemistry corresponds to the larger field within the area of Exact Sciences in Brazil. In this triennial, there was a $40 \%$ increase in the number of programs (from 44 to 61), simultaneously with decentralization in the geographic distribution of graduate programs with the appearance of new centers in the North, Northeast, Central-West and far South regions of Brazil. Concurrently, there was an increase in the international visibility of Brazilian programs in Chemistry, which can be verified in the ESI-ISI data bank (Essential Science Indicators - Institute for Scientific Information). Included in this database, containing 65,000 institutions in the field of chemistry, we have eleven Brazilian institutions that are ranked in the one per cent of the world's most productive institutions. Nevertheless, much progress is still needed in the assessment process, especially when we try to compare areas which are widely different. For example, how will it be possible to guarantee that an Arts course with a classification of 6 is equivalent to a 6 in Physics or Chemistry? The instruments for comparison among the greater part of the study fields are already available and are internationally recognized. The challenge now is to apply them!

Jairton Dupont IQ - UFRGS 